УДК 532.135

DOI 10.18101/2306-2363-2019-1-24-31

\title{
ВЯЗКОСТЬ НАНОСУСПЕНЗИИ ФУЛЛЕРЕНОВ В ПОЛИМЕРНОЙ ЖИДКОСТИ
}

\section{(C) Е. Д. Вершинина}

аспирант,

Институт физического материаловедения СО РАН

670047, Улан-Удэ, ул. Сахьяновой, 6

E-mail: vershininaed@mail.ru

\section{(C) Т. С. Дембелова}

доктор технических наук, ведущий научный сотрудник, Институт физического материаловедения СО РАН 670047, Улан-Удэ, ул. Сахьяновой, 6

E-mail: tu dembel@mail.ru

\section{(C) Д. Н. Макарова}

научный сотрудник,

Институт физического материаловедения СО РАН

670047, Улан-Удэ, ул. Сахьяновой, 6

E-mail: dagzama@mail.ru

\section{(C) Б. Б. Бадмаев}

доктор технических наук, заведующий лаборатории физики молекулярных структур, Институт физического материаловедения СО РАН

670047, Улан-Удэ, ул. Сахьяновой, 6

Восточно-Сибирский государственный университет технологий и управления 670047, Улан-Удэ, ул. Ключевская, 40В

E-mail:1mf@ipms.bscnet.ru

В работе экспериментально изучена вязкость наносуспензий фуллеренов $\mathrm{C}_{60}$ в полиэтилсилоксановой жидкости (ПЭС-2, ПЭС-4). Получены зависимости напряжения сдвига от скорости сдвига и вязкости от времени. Результаты измерения вязкости суспензий капиллярным вискозиметром и реометром вполне согласуются между собой в пределах точности измерения. Вязкость суспензий выше вязкости базовых жидкостей. Исследования важны для получения эффективной по вязкости и концентрации суспензий для разных практических приложений.

Ключевые слова: наносуспензии; фуллерены; вязкость; полиэтилсилоксановая жидкость; нановключения; наночастицы; микроэлектромеханические системы.

\section{Для цитирования:}

Вершинина Е. Д., Дембелова Т. С., Макарова Д. Н., Бадмаев Б. Б. Вязкость наносуспензии фуллеренов в полимерной жидкости // Вестник Бурятского государственного университета. Химия. Физика. 2019. Вып. 1. С. 24-31.

Наносуспензии - это двухфазные системы, состоящие из дисперсионной среды и внедренных в нее наночастиц с размерами от 1 до 100 нм. Самой маленькой наночастицей можно считать фуллерен, диаметр которого около 1 нм. В 
Е. Д. Вершинина, Т. С. Дембелова, Д. Н. Макарова, Б. Б. Бадмаев. Вязкость наносуспензии фуллеренов в полимерной жидкости

качестве дисперсионной среды применяются вода, органические жидкости (этиленгликоль, различные масла, биологические и полимерные жидкости). В качестве дисперсной фазы используются частицы химически устойчивых металлов, их оксидов, фуллерены, углеродные нанотрубки и другие. В результате их смешивания образуется структурированная дисперсная система, которая обладает особыми физико-механическими свойствами. Эта структура определяется характером взаимодействия наночастиц между собой и со средой. При нарушении состояния равновесия структура этих систем разрушается. Характер образования и разрушения структуры дисперсной системы определяются их структурномеханическими свойствами как вязкость, упругость, пластичность и прочность. В работах $[1,2]$ акустическим резонансным методом исследован низкочастотный $\left(10^{5}\right.$ Гц) комплексный модуль сдвига коллоидных суспензий наночастиц диоксида кремния, иттрий-алюминиевого граната. Рассчитаны значения модуля сдвига, тангенса угла механических потерь, эффективной вязкости, исследованы зависимости этих параметров от амплитуды сдвиговых воздействий, определены предельные напряжения сдвига, с которой начинается разрушение равновесной структуры суспензии.

Особые физико-механические свойства наносуспензии позволяют их использовать в создании микроэлектромеханических систем (МЭМС), при создании систем транспортировки тепловой энергии, в экологии, при разработке новых лекарственных препаратов, смазочных материалов, лаков и красок. Широкое использование наносуспензии в нанотехнологиях различного назначения требует всесторонних исследований их реологических свойств.

Активные реологические исследования вязкости суспензий наночастиц ведутся лишь последние два десятилетия. Известные в литературе результаты экспериментальных измерений вязкости суспензии наночастиц неоднозначны, порой даже противоречивы. Однако установлено, что коэффициент вязкости суспензии зависит от размеров, природы и концентрации нановключений [3-8].

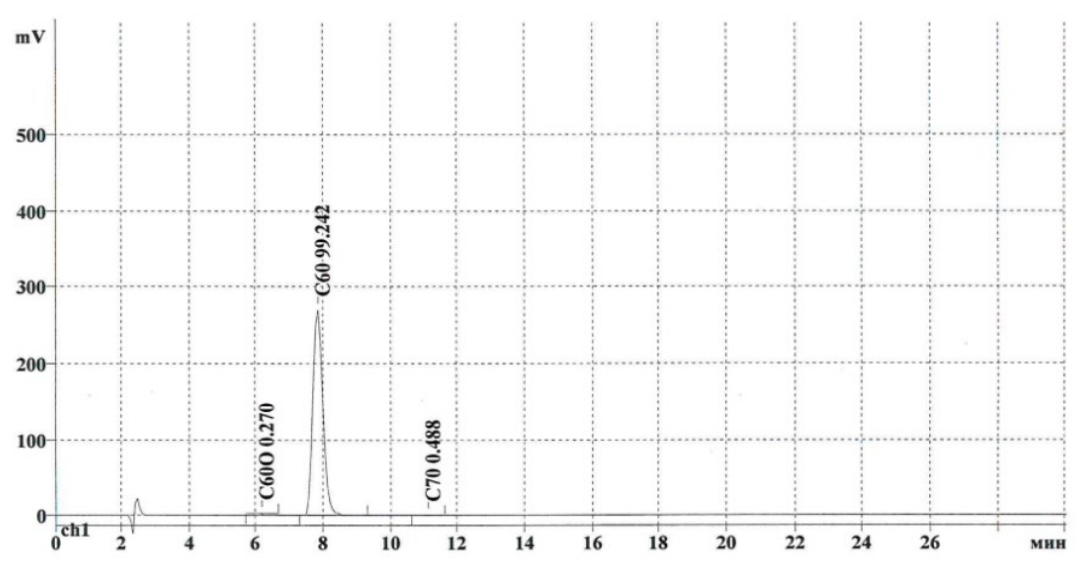

Рис. 1. Хроматограмма смеси фуллеренов $\mathrm{C}_{60} / \mathrm{C}_{70}$ 
В данной работе приводятся результаты исследования динамической вязкости суспензии фуллеренов. В качестве дисперсной среды использованы полиэтилсилоксановые (ПЭС) жидкости, которые относятся к поверхностноактивным жидкостям и хорошо смачивают внедренные в них наночастицы. Для получения суспензии использована смесь фуллеренов $\mathrm{C}_{60} / \mathrm{C}_{70}$, приобретенная в ООО НПК «НеоТекПродакт». Хроматограмма концентрата $\mathrm{C}_{60}$ представлена на рис. 1 , из которой видно, что содержание фуллеренов $\mathrm{C}_{60}$ составляет $99.24 \%$.

Свойства дисперсных систем зависят от степени дисперсности нановключений. Наночастицы обладают большой поверхностной энергией и при их внедрении в дисперсную среду образуют агломераты. Размеры агломератов могут достичь нескольких микронов. Поэтому для получения устойчивой суспензии важным является ее тщательное диспергирование, которое позволяет предельно разрушить агломераты наночастиц. Кроме того, при диспергировании наносуспензии устанавливается равномерное распределение наночастиц в объеме дисперсной среды.

Диспергирование наносуспензии проведено нами на ультразвуковом технологическом аппарате УЗТА-0,4/22-ОМ "Волна", у которого частота механических колебаний $22 \pm 1,65$ кГц, максимальная потребляемая мощность 400 Вт, диапазон регулирования мощности $30-100 \%$, интенсивность ультразвукового воздействия не менее $50 \mathrm{BT} / \mathrm{cm}^{2}$. Вибрирующий стержень аппарата опускался в пробирку с суспензией, которая подвергалась ультразвуковому воздействию. Время диспергирования для суспензии $\mathrm{C}_{60} /$ ПЭС-2 составило 4 мин, а для $\mathrm{C}_{60} /$ ПЭС-4-8 мин.

Распределение частиц по размерам в полученной суспензии определялось на лазерном анализаторе размеров частиц SALD-7500 nano в ЦКП «Научные приборы» ФГБОУ ВО «Бурятский государственный университет». Показано, что в суспензиях $\mathrm{C}_{60} /$ ПЭС-2 и $\mathrm{C}_{60} /$ ПЭС-4 средний размер наночастиц составил 7 нм (рис. 2,3 ), к сожалению, это нижняя граница доступного диапазона измерений анализатора.

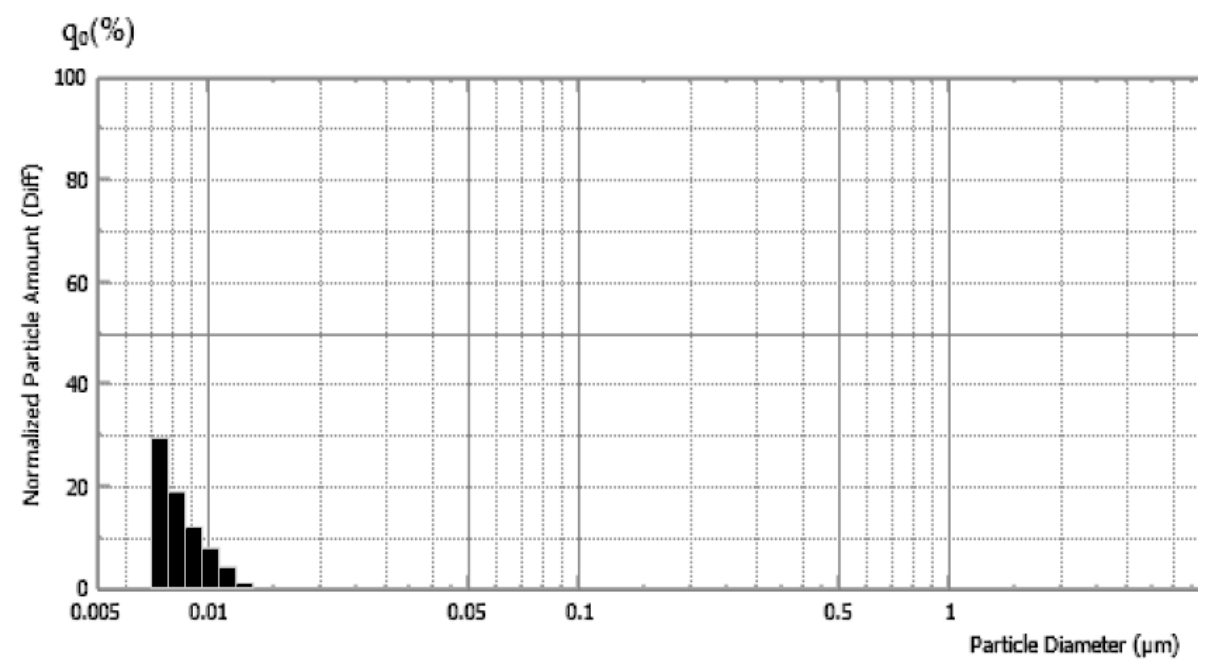

Рис. 2. Распределение частиц $\mathrm{C}_{60}$ по размерам в суспензии $\mathrm{C}_{60} /$ ПЭС-2 
Е. Д. Вершинина, Т. С. Дембелова, Д. Н. Макарова, Б. Б. Бадмаев. Вязкость наносуспензии фуллеренов в полимерной жидкости

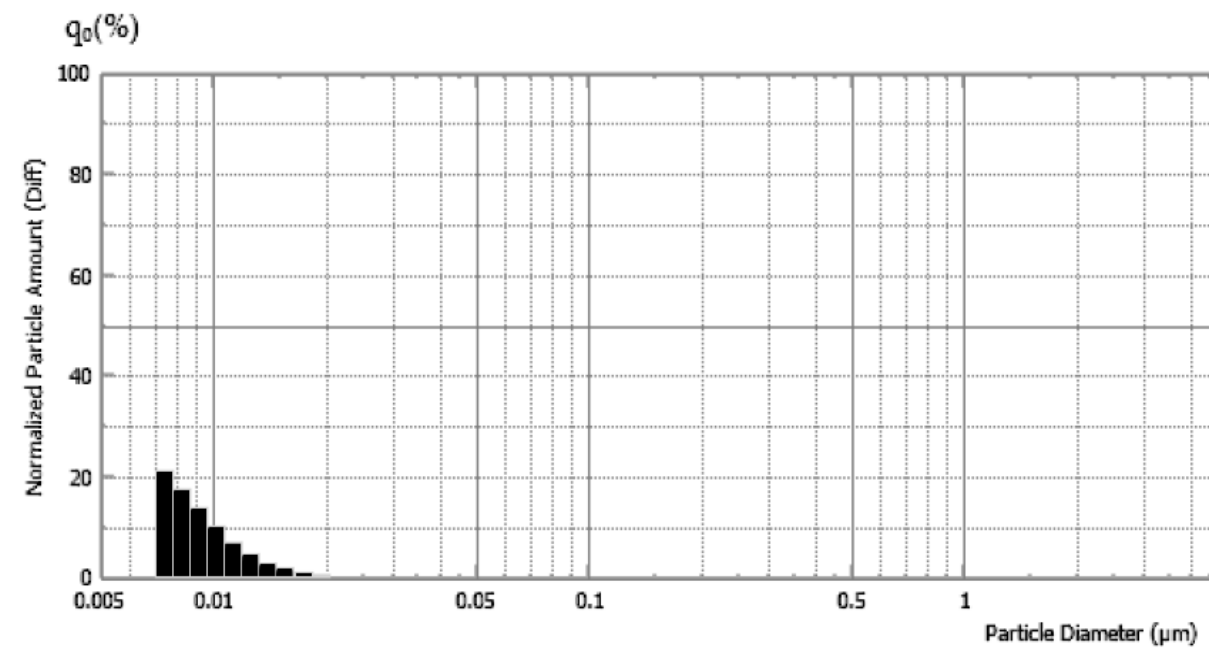

Рис. 3. Распределение частиц $\mathrm{C}_{60}$ по размерам в суспензии $\mathrm{C}_{60} / П Э С-4$

Исследование динамического коэффициента вязкости суспензии фуллеренов в ПЭС жидкости проводили на реометре Anton Paar MCR 52 в ЦКП «Научные приборы» ФГБОУ ВО «Бурятский государственный университет». Использовалась система конус - плоскость с зазором 0,1 мм. Использование такой системы обеспечивает одинаковые деформации всех элементов среды в процессе измерений. Диаметр конуса составлял 49,967 мм, угол между образующей конуса и плоскостью измерений $-0,986^{\circ}$. Реометр имеет систему термостабилизации с точностью до $0,01^{\circ} \mathrm{C}$. Измерения проводились при температуре $23^{\circ} \mathrm{C}$.

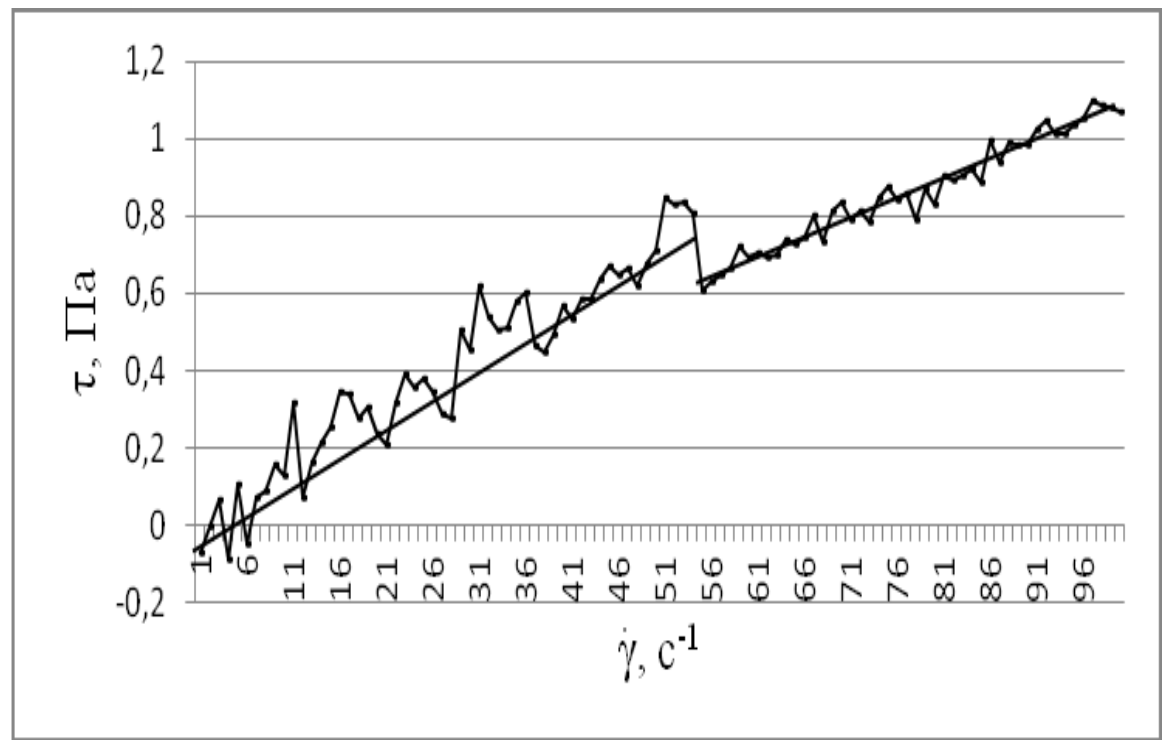

Рис. 4. Зависимость напряжения сдвига от скорости сдвига для суспензии С60/ПЭС-2 


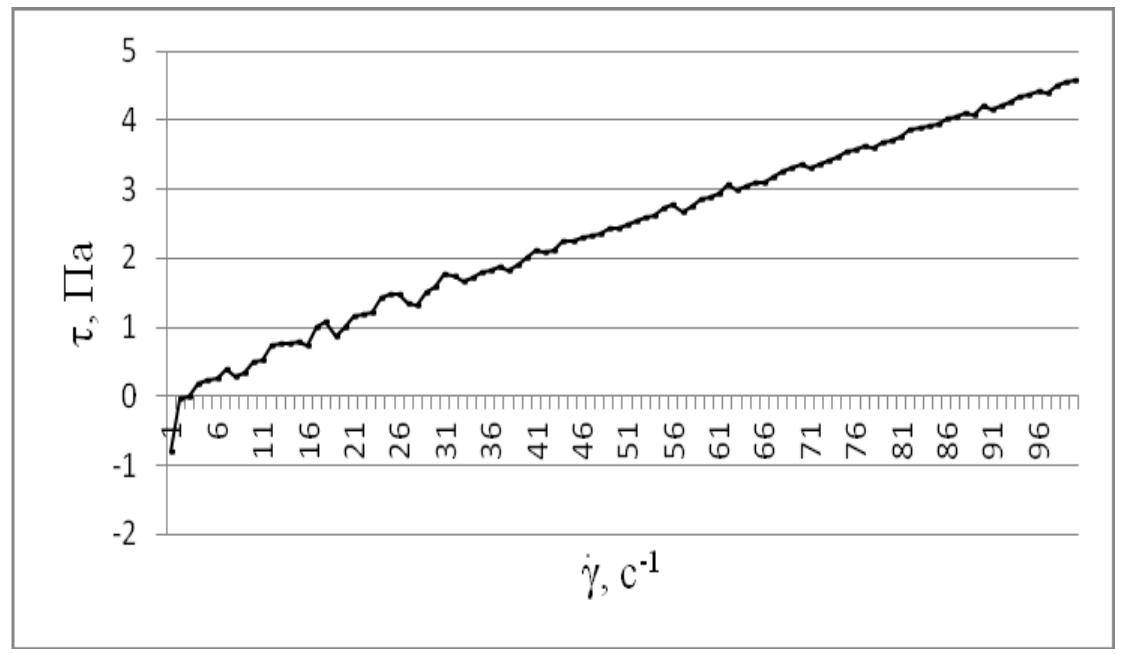

Рис. 5. Зависимость напряжения сдвига от скорости сдвига для суспензии С $60 / П Э С-4$

Как известно, вязкость жидкостей обычно подчиняется закону Ньютона. Этот закон устанавливает наличие линейной зависимости между напряжением сдвига $\tau$ и скоростью сдвига $\dot{\gamma}$, т.е. $\tau=\eta \cdot \dot{\gamma}$. Угол наклона линейной зависимости определяет коэффициент вязкости $\eta$. На рис. 4 представлена экспериментальная

Как известно, вязкость жидкостей обычно подчиняется закону Ньютона. Этот закон устанавливает наличие линейной зависимости между напряжением сдвига $\tau$ и скоростью сдвига $\dot{\gamma}$, т.е. $\tau=\eta \cdot \dot{\gamma}$. Угол наклона линейной зависимости определяет коэффициент вязкости $\eta$. На рис. 4 представлена экспериментальная зависимость напряжения сдвига от скорости сдвига для суспензии С 60 /ПЭС-2, полученная на реометре Anton Paar MCR 52. По отклонению линии тренда видно, что зависимость имеет нелинейный характер. Это значит, что кривая течения суспензии отклоняется от ньютоновского поведения, т. е. вязкость зависит от скорости сдвига. А на рис. 5 представлена зависимость напряжения сдвига от скорости сдвига для суспензии $\mathrm{C}_{60} /$ ПЭС-4. Здесь наблюдается линейная зависимость, и суспензия проявляет ньютоновское поведение. Измерения показали, что для суспензии $\mathrm{C}_{60} /$ ПЭС-2 с концентрацией 1,5 масс.\% получено значение коэффициента вязкости 11,58 мПа·с, а для суспензии $\mathrm{C}_{60} /$ ПЭС-4 с той же концентрацией - значение коэффициента вязкости 47,13 мПа·с.

На рис. 6 показаны зависимости коэффициентов вязкости исследуемых суспензий от времени при постоянной скорости деформации.

Из рисунков видно, что коэффициент вязкости суспензии $\mathrm{C}_{60} /$ ПЭС-2 со временем несколько растет, а коэффициент вязкости суспензии $\mathrm{C}_{60} /$ ПЭС-4 не меняется. Это говорит о том, что для $\mathrm{C}_{60} /$ ПЭС-4 получена более устойчивая по сравнению с $\mathrm{C}_{60} /$ ПЭС-2 структура. В суспензии $\mathrm{C}_{60} /$ ПЭС-2 вероятно происходит уменьшение агломератов под действием вращающегося конуса реометра за время наблюдения. Из литературы известно, что коэффициент вязкости наносуспензии растет с уменьшением размера частиц $[1,9,10]$. 
Е. Д. Вершинина, Т. С. Дембелова, Д. Н. Макарова, Б. Б. Бадмаев. Вязкость наносуспензии фуллеренов в полимерной жидкости

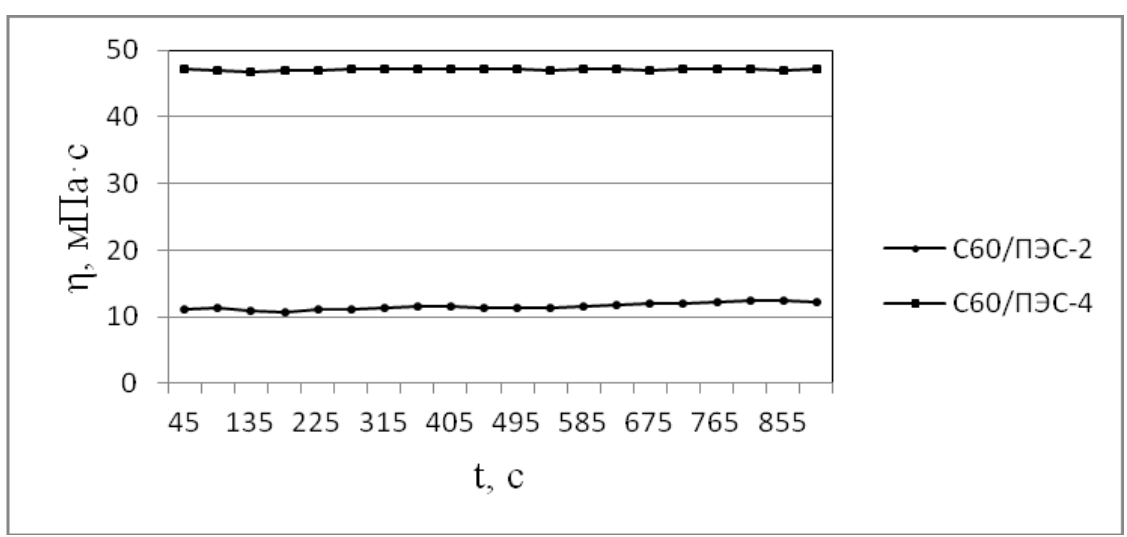

Рис. 6. Зависимость коэффициента вязкости суспензии С $60 /$ ПЭС-2 и С $60 /$ ПЭС-4 от времени

Также коэффициенты вязкости суспензий и базовых жидкостей измерялись капиллярным вискозиметром ВПЖ-2, при постоянной температуре $23^{\circ} \mathrm{C}$. В таблице приводятся значения коэффициентов вязкости суспензий и ПЭС жидкостей, полученные на реометре Anton Paar MCR 52 и на вискозиметре ВПЖ-2.

Таблица

Значения коэффициентов вязкости суспензий и ПЭС жидкостей

\begin{tabular}{|c|c|c|c|c|c|}
\hline Прибор & $\stackrel{\mathrm{t},}{{ }^{\circ} \mathrm{C}}$ & $\begin{array}{c}\eta_{\text {С60/ПЭС-2 }} \\
1.5 \text { масс.\%, мПа·с }\end{array}$ & $\begin{array}{l}\eta_{\Pi \ni с-2,} \\
\mathrm{мПа} \cdot \mathrm{c}\end{array}$ & $\begin{array}{c}\eta_{\text {С60/ПЭС-4 }} \\
1.5 \text { масс.\%, мПа·с }\end{array}$ & $\begin{array}{l}\text { १ПЭС-4, } \\
\text { мПа с }\end{array}$ \\
\hline $\begin{array}{l}\text { Anton Paar } \\
\text { MCR } 52\end{array}$ & 23 & 11,58 & 9,85 & 47,13 & 41,68 \\
\hline ВПЖ-2 & 23 & 10,78 & 9,74 & 46,41 & 40,82 \\
\hline
\end{tabular}

Видно, что результаты измерения вязкости суспензии капиллярным вискозиметром и реометром вполне согласуются между собой в пределах точности измерения. Из таблицы также видно, что вязкость суспензий выше вязкости базовых жидкостей.

В дальнейшем предполагаются исследования вязкости суспензий в зависимости от размеров и концентраций наночастиц. Эти исследования важны для получения эффективной по вязкости и концентрации суспензий для разных практических приложений.

Работа выполнена при поддержке гранта РФФИ № 18-48-030020.

\section{Литература}

1. Дембелова Т. С., Цыренжапова А. Б., Макарова Д. Н., Дамдинов Б. Б., Бадмаев Б. Б. Акустическое исследование сдвиговых вязкоупругих свойств коллоидных суспензий наночастиц // Ученые записки физического факультета Московского университета. - 2014. — № 5. - C. 145301-1-145301-4.

2. Damdinov B., Dembelova T., Badmaev B., Barnakov Yu. Structural Research of Nanoparticles Dispersions // Solid State Phenomena. — 2019. — V. 288. — P.130-134. 
3. Рудяк В. Я., Белкин А. А. Моделирование коэффициентов переноса наножидкостей // Наносистемы: физика, химия, математика. - 2010. - Т. 1, № 1. - С. 156-177.

4. Saidur R., Leong K. Y., Mohammad H. A. A review on applications and challenges of nanofluids // Renewable and Sustainable Energy Reviews. - 2011. - V. 15. - P. 1646-1668.

5. Mahbubul I.M., Saidur R., Amalina M.A. Latest developments on the viscosity of nanofluids // Intern. of J.Heat and Mass Transfer. - 2012. - V. 55. - P. 874-885.

6. Chevalier J., Tillement O., Ayela F. Rheological properties of nanofluids flowing through microchannels // Appl. Phys. Lett. - 2007. - V. 91, № 23. - P. 233103.

7. He Y., Jin Y., Chen H., Ding Y., Cang D., Lu H. Heat transfer and flow behaviour of aqueous suspensions of $\mathrm{TiO} 2$ nanoparticles (nanofluids) flowing upward through a vertical pipe // Intern. J. Heat and Mass Transfer. - 2007. - V. 50, № 11. - 12. - P. 2272-2281.

8. Рудяк В. Я. Современное состояние исследований вязкости наножидкостей // Вестник НГУ. Серия: Физика. — 2015. - Т. 10, Вып. 1. — С. 5-22.

9. Рудяк В. Я., Балкин А. А., Егоров В. В. Об эффективной вязкости наносуспензий // ЖТФ. - 2009. - Т. 79, Вып. 8. - С. 18-25.

10. Namburu P. K., Kulkarni D. P., Dandekar A. and Das D. K. Experimental investigation of viscosity and specific heat of silicon dioxide nanofluids // Micro \& Nano Letters. - 2007. V. 2, № 3. - P. 67-71

\section{THE VISCOSITY OF FULLERENES NANOSUSPENSION IN POLYMERIC LIQUIDS}

\section{E. D. Vershinina}

Postgraduate

Institute of Physical Materials Sciences SB RAS

670047, Ulan-Ude, Sakhyanova Str., 6

E-mail: vershininaed@mail.ru

\section{T. S. Dembelova}

Doctor of Technical Sciences, Leading Researcher Institute of Physical Materials Sciences SB RAS

670047, Ulan-Ude, Sakhyanova Str., 6

E-mail: tu_dembel@mail.ru

D. N. Makarova

Researcher

Institute of Physical Materials Sciences SB RAS

670047 Ulan-Ude, Sakhyanova Str., 6

E-mail: dagzama@mail.ru

\section{B.B. Badmaev}

Doctor of Technical Sciences

Head of Laboratory of Molecular Structure Physics

Institute of Physical Materials Sciences SB RAS

670047 Ulan-Ude, Sakhyanova Str., 6

Associate Professor Physics

East Siberian State University of Technology and Management

670047 Ulan-Ude, Kluchevskaya, 40V

E-mail:1mf@ipms.bscnet.ru 
Е. Д. Вершинина, Т. С. Дембелова, Д. Н. Макарова, Б. Б. Бадмаев. Вязкость наносуспензии фуллеренов в полимерной жидкости

The viscosity of nanosuspensions of fullerenes C60 in polyethylsiloxane liquid (PES-2, PES-4) was experimentally investigated. Dependences of shear stress on shear rate and viscosity on time are obtained. The results of measuring viscosity of suspensions by capillary viscometer and rheometer are consistent within the measurement accuracy. Viscosity of suspensions is higher than viscosity of base liquids. Studies are important for obtaining effective viscosity and concentration suspensions for different applications.

Keywords: nanosuspension; fullerenes; viscosity polyethylsiloxane liquid; nanocluster; nanoparticles; micro-electromechanical systems. 